\title{
Variations in growth traits and wood physicochemical properties among Pinus koraiensis families in Northeast China
}

\author{
Qinhui Zhang ${ }^{1,2} \cdot$ Xiaona Pei $^{1} \cdot$ Xianbo Lu $^{1,2} \cdot$ Chunli Zhao $^{1} \cdot$ Guangzhi Dong $^{3}$. \\ Wanling $\mathrm{Shi}^{3} \cdot$ Liankui Wang ${ }^{3}$ Yanlong $\mathrm{Li}^{3} \cdot$ Xiyang Zhao $^{1,2} \cdot$ Mulualem Tigabu $^{4}$
}

Received: 13 September 2021 / Accepted: 4 November 2021 / Published online: 24 January 2022

(C) The Author(s) 2022

\begin{abstract}
This study aimed to explore and improve the different economic values of Pinus koraiensis (Siebold and Zucc.) by examining the variations in 6 growth traits and 9 physicochemical wood properties among 53 P. koraiensis half-sib families. Growth traits assessed included height, diameter at breast height, volume, degree of stem straightness, stem form, and branch number per node, while wood properties assessed included density, fiber length and width, fiber length to width ratio, and cellulose, hemicellulose, holocellulose, lignin, and ash contents. Except for degree of stem straightness and branch number per node, all other traits exhibited highly significant variations $(P<0.01)$ among families. The coefficients of variation ranged from 5.3 (stem form) to $66.7 \%$ (ash content), whereas, the heritability ranged from 0.136 (degree of stem straightness) to
\end{abstract}

Qinhui Zhang, Xiaona Pei and Xianbo Lu made equal contributions to this paper.

Project funding:This work was financially supported by the fundamental Research Funds for the Central Universities (2572020DR01) and HeilongjiangTouyan Innovation team program (Tree Genetics and Breeding Innovation Team).

The online version is available at http://www.springerlink.com.

Corresponding editor: Yu Lei.

Xiyang Zhao

zhaoxyphd@163.com

Mulualem Tigabu

Mulualem.Tigabu@slu.se

1 College of Forestry and Grassland, Jilin Agricultural University, Changchun 130118, People's Republic of China

2 State Key Laboratory of Tree Genetics and Breeding, Northeast Forestry University, Harbin 150040,

People's Republic of China
0.962 (ash content). Significant correlations were observed among growth traits and wood physicochemical properties. Principal component analysis identified four distinct groups representing growth traits, wood chemical and physical properties, and stem form traits. Multi-trait comprehensive evaluation identified three groups of elite families based on breeding objectives, including rapid growth, improved timber production for building and furniture materials, and pulpwood production. These specific families should be used to establish new plantations.

Keywords Growth and wood traits · Pinus koraiensis . Principal component analysis · Family selection . Economic benefits

\section{Introduction}

Pinus koraiensis (Sieb. and Zucc.) is an economically valuable species in Northeast China (Wang et al. 2015), and an important protected plant in the country (Zhang et al. 2015a, b). It is generally distributed in the mountains of Xiaoxing' an, Wanda, Zhangguangcai, Laoye, and Changbai (Xia et al. 1991). P. koraiensis wood is of high quality (Son et al. 2001) with strong corrosion resistance; the seeds have

3 Sanchazi Forestry Bureau of Jilin Province, Baishan 134702, People's Republic of China

4 Southern Swedish Forest Research Centre, Swedish University of Agricultural Sciences, PO Box 49, 23053 Alnarp, Sweden 
high nutritional value and are marketed as pine nuts (Imbs and Pham 1996). To improve these economic benefits, $P$. koraiensis should be established in seed orchards as sources of quality regeneration material for future plantations (Xue et al. 2009).

A seed orchard is important to improve forest productivity (Kjaer and Foster 1996). Numerous coniferous plantations world-wide have originated from seed orchards (Lindgren and Prescher 2005). In some areas, the establishment of third-generation seed orchards has been achieved (Chen and Shen 2005). China began to establish the clonal seed orchard of Cedrus atlantica (Endl.) Manetti ex Carriere in 1964 (Wang 2013). Today, over 20 tree species have established in seed orchards (Chen 2001). Similarly, large-scale breeding of $P$. koraiensis in China began in the 1980 s, and researchers mainly selected materials from natural $P$. koraiensis forests (Liu 2017). However, most of these seed orchards are in the primary stages because $P$. koraiensis is characterized by slow growth (Liu et al. 2015).

Currently, several $P$. koraiensis research programs are primarily concerned with the study of chemical components of pine nuts (Kim et al. 2012; Shpatov et al. 2017; Lee et al. 2018), the identification of molecular markers (Kim et al. 2005; Chen et al. 2011), asexual reproduction techniques (Liu 2004; Song et al. 2007), the establishment of seed orchards (Oh et al. 2008; Feng et al. 2010) and eco-physiological attributes (Makoto and Koike 2007; Sun et al. 2016). There has been limited conventional breeding research on $P$. koraiensis although the evaluation of progenies from seed orchards can serve as materials for the selection of elite families and single plants.

In this study, variations in growth traits and wood physicochemical properties among $P$. koraiensis families were evaluated. Growth and wood traits are crucial reference standards in tree breeding, particularly as a reference for selecting high performance families and clones for the establishment of seed orchards (Zhang et al. 2017). The economic value of wood is determined by its material properties, and this directly affects wood processing and utilization ( $\mathrm{Li}$ et al. 2018). Earlier studies focused on selection and application of growth trait variation (Zhen et al. 2007), but the genetic gain of a single pursuit of growth traits may lower wood quality (Li et al. 2014). In addition, reports indicate that growth traits are weakly or negatively correlated with wood density (Ru et al. 2001; Su 2001). Therefore, simultaneous selection of growth and wood traits is of considerable significance towards achieving greater economic benefits. $P$. koraiensis wood is used in building and furniture construction; however, reports on $P$. koraiensis pulpwood are scarce. This paper investigates the economic value of $P$. koraiensis to improve them.

A targeted evaluation method can be applied to select families and clones with superior genetic stability according to different breeding objectives (Matziris 1997; Wu et al. 2018). Several evaluation methods are available (Luo et al. 2010). In this study, the multi-character comprehensive evaluation method was used. Half-sib progenies of $P$. koraiensis of the Jilin Provincial Forestry Bureau were used as research materials to: (1) evaluate the variations in growth traits and wood physicochemical properties among 53 P. koraiensis half-sib families, and search for links between growth and wood traits; (2) select high performance families based on different breeding goals; and, (3) provide a new approach for the improvement of $P$. koraiensis to increase productivity and improve economic benefits.

\section{Materials and methods}

\section{Experimental site}

The experimental site was the Sanchazi seed orchard, $126^{\circ} 56^{\prime} \mathrm{E}, 41^{\circ} 95^{\prime} \mathrm{N}$ in Baishan City, Jilin Province at an altitude of $520 \mathrm{~m}$. The area is characterized by a temperate continental monsoon climate with an average annual temperature of $2.5{ }^{\circ} \mathrm{C}$, annual precipitation of $725.5 \mathrm{~mm}$, and annual sunshine of $2,300 \mathrm{~h}$, with a frost-free period of $110 \mathrm{~d}$.

\section{Progeny plantation}

For this study, seeds of 53 half-sib families [(family 1, 10, 49, 65, 77, 82, 83, 84, 85, 87, 88, 90, 91, 92, 93, 94, 96, 97, $98,100,101,102,103,105,106,108,109,110,111,112$, $113,114,115,117,118,120,122,125,129,130,132,133$, 134, 135, 136, 137, 138, 140, 143, 144, 145, 148, 163),] each with 6 individuals, were acquired from the Sanchazi seed orchard, planted in the spring of 1990 in the nursery and cultivated for 4 years. The progeny plantation was established in 1995 in the spring as a completely randomized block design with 5 blocks and 6 replicates in each plot in rows at $2.0 \mathrm{~m} \times 3.0 \mathrm{~m}$ spacing.

\section{Growth traits measurements}

Growth traits included height $(\mathrm{H})$, diameter at breast height (DBH), volume (V), degree of stem straightness (SSD), stem fullness (SF), and branch number per node (BNN), which were measured at 24 years. SSD was estimated according to Zhao et al. (2014) in a scale of $1-5$. A tree with more than two obvious bends in the stem received a score of 1 , those with more than two slight bends or with one obviously bend scored 2 , those with two slight bends scored 3, those with one slight bend received a score of 4 , 
and finally, those with a completely straight stem scored 5. The SSD values were squared before ANOVA. SF was estimated as the ratio of DBH to basal diameter. Volume was calculated following Zhang et al. (2014) as follows:

$V=\pi\left(D_{1.3} / 2\right)^{2}(H+3) f$

where, $f$ denotes the form factor of $P$. koraiensis as 0.33 ; and $D_{1.3}$ denotes the DBH.

\section{Wood traits measurements}

Fifteen wood cores per family (one per tree and three trees per block) were taken from the north to south sides of the stem at $1.3 \mathrm{~m}$ (Luo et al. 2004), wrapped in straw and transported to the laboratory for analysis (Sun et al. 2018). Wood density (WD), fiber length (FL), fiber width (FW), fiber length to width ratio (LWR), cellulose (CC), hemicellulose (HEC), holocellulose (HOC), lignin (LC), and ash (AC) contents were determined. WD was determined as described by Li et al.(2018) using five wood cores for each family. Thirty FLs and FWs were measured on five cores per each family that were mixed (Tang et al. 2018), and LWR was calculated. Dry matter production (DMP), as the product of $\mathrm{WD}$ and $\mathrm{V}$, and cellulose production (CP), as the product of DMP and CC, were calculated for each family.

The remaining wood cores were ground in a ball mill and mixed to determine chemical properties using an ANKOM A2000i automatic fiber analyzer following Liu (2017). Neutral detergent fiber (NDF) was determined following the digestion of neutral washing solution, and the residues include hemicellulose, cellulose, and lignin. Acid detergent fiber (ADF) was determined following the digestion of the acid washing solution, and the residues include cellulose and lignin. Acid detergent lignin (ADL) treated with $72 \%$ sulfuric acid resulted in a lignin residue. Cellulose (CC), HEC, HOC, and LC were determined using the following relationships:

$$
\begin{aligned}
& P_{H E C}=P_{N D F}-P_{A D F} \\
& P_{C C}=P_{A D F}-P_{A D L} \\
& P_{H O C}=P_{N D F}-P_{A D L} \\
& P_{L C}=P_{A D L}-P_{A C}
\end{aligned}
$$

where $P_{H E C}, P_{C C}, P_{H O C}$ and $P_{L C}$ denote percentage hemicellulose (HEC), cellulose (CC), holocellulose (HOC), lignin (LC) contents; and $P_{N D F}, P_{A D F}, P_{A D L}$ and $P_{A C}$ denote percentage neutral detergent fiber (NDF), acid detergent fiber (ADF), acid detergent lignin (ADL) and ash contents (AC).

\section{Statistical analysis}

The significant variations in growth traits among families and blocks were tested by ANOVA using the following linear model (Xia et al. 2016):

$X_{i j k}=\mu+\alpha_{i}+b_{j}+\alpha b_{i j}+e_{i j k}$

where $X_{i j k}$ denotes the observation value of the $k$ th individual tree in the $i$ th family growing in $j$ th block, $\mu$ the family mean, $\alpha_{i}$ the family effects, $b_{j}$ the block effect, $\alpha b_{i j}$ the effect of the interaction between family $i$ and block $j, e_{i j k}$ represent the random error.

Family variations in wood traits were analyzed using the following linear model:

$Y_{i j}=\bar{X}+E_{i j}$

where $Y_{i j}$ denotes the observation value of $j$ th individual tree in $i$ th family, $\bar{X}$ the family mean, $E_{i j}$ the random error.

Phenotypic coefficient of variation (PCV) was calculated using the following formula (Metougui et al. 2017):

$P C V=\frac{\sqrt{\sigma_{p}^{2}}}{\bar{X}} \times 100 \%$

where $\sigma_{p}^{2}$ denotes the phenotypic variance component of a given trait.

Heritability of growth $\left(h^{2}\right)$ and heritability of wood traits $\left(h_{f}^{2}\right)$ were calculated according to Eqs. 9 and 10 (Li 2018):

$h^{2}=\frac{\sigma_{f}^{2}}{\sigma_{f}^{2}+\sigma_{b}^{2} / b+\sigma_{e}^{2} / n b}$

$h_{f}^{2}=\frac{\sigma_{f}^{2}}{\sigma_{f}^{2}+\sigma_{e}^{2} / r}$

where $\sigma_{f}^{2}$ denotes variance component for the family effect, $\sigma_{b}^{2}$ the variance component for family by block interaction effects, and $\sigma_{e}^{2}$ the residual error, $\mathrm{b}$ represents the number of blocks, $\mathrm{n}$ the number of plots, and $\mathrm{r}$ the number of values per family.

The phenotypic correlation between traits was computed according to Han et al. (2017):

$r_{P}(x, y)=\frac{\operatorname{Cov}_{P}(x, y)}{\sqrt{\sigma_{P_{x}}^{2} \cdot \sigma_{P_{y}}^{2}}}$ 
where $\operatorname{Cov}_{P}(x, y)$ denotes phenotypic covariance between trait $\mathrm{x}$ and $\mathrm{y}$, and $\sigma_{P_{x}}^{2}$ and $\sigma_{P_{y}}^{2}$ represent the phenotypic variance component for trait $\mathrm{x}$ and $\mathrm{y}$, respectively.

The comprehensive evaluation values $\left(Q_{i}\right)$ for different families were computed following Zhao et al. (2016):

$Q_{i}=\sqrt{\sum_{j=1}^{n} a_{i}}$

where ai is $\mathrm{Xij} / \mathrm{Xjmax}$; and $\mathrm{Xij}, \mathrm{Xjmax}$ and $\mathrm{n}$ denote the average value of a trait, the maximum value of the trait and the number of traits, respectively.

The genetic gain $(\Delta G)$ was estimated following Silva et al. (2008), and the real gain $\left(\Delta G_{r}\right)$ following Ye (2011) as follows:

$\Delta G=h^{2} \Delta S / \bar{X} \times 100 \%$

$\Delta G_{r}=S / \bar{X} \times 100 \%$

where $h^{2}$ is heritability; $\Delta S$ and $\mathrm{S}$ are the differential of selection; $\bar{X}$ is the family mean. All statistical analysis were performed using Statistical Product and Service Solution (SPSS) software, version 26.0 (IBM Corp., Armonk, NY, USA).

\section{Results}

\section{Variations in growth and wood traits}

Highly significant differences $(P<0.01)$ in growth traits among families and blocks were detected; except for SSD (degree of stem straightness) and BNN (branch number per node) but the interactions were significant for all growth traits (Table 1). Similarly, there were significant differences in wood traits among families (Table 2). There were moderate variations in growth traits, particularly in volume and high variation in ash content (Table 3). The PCV of traits ranged from $5.33 \%$ for stem form of $66.67 \%$ for ash content (Table 3). The $\mathrm{PCV}$ of volume, fiber length, fiber length to width ratio, and hemicellulose content were larger than $25 \%$, whereas the PCV of stem fullness and wood density were less than $10 \%$. The $h^{2}$ of growth traits was $>0.7$ except for height and degree of stem straightness, in which the $h^{2}$ of $\operatorname{SSD}(0.136)$ was minimal (Table 3). The $h^{2}$ of each wood trait was $>0.8$. The highest $h^{2}$ was for lignin content $(0.960)$ and ash content $(0.962)$.

\section{Correlation analysis}

There were highly significant $(p<0.01)$ positive correlations between $\mathrm{H}, \mathrm{DBH}$ and $\mathrm{V}$, with strong correlation $(r=0.98)$ between DBH and V (Fig. 1). SF (stem fullness) showed a significant $(p<0.01)$ correlation with $\mathrm{H}(0.49)$, DBH $(0.67)$,
Table 1 ANOVA results for examining variations in growth traits among families and blocks

\begin{tabular}{lllrr}
\hline Traits & Variance source & df & \multicolumn{1}{c}{ MS } & \multicolumn{1}{l}{ F } \\
\hline Height & Family & 52 & 3.514 & $1.783^{* *}$ \\
& Block & 4 & 35.345 & $17.932^{* *}$ \\
DBH & Family $\times$ Block & 208 & 1.971 & $7.739^{* *}$ \\
& Family & 52 & 60.532 & $3.939^{* *}$ \\
& Block & 4 & 93.515 & $6.085^{* *}$ \\
Volume & Family $\times$ Block & 208 & 15.368 & $4.415^{* *}$ \\
& Family & 52 & 0.007 & $3.928^{* *}$ \\
& Block & 4 & 0.017 & $9.542^{* *}$ \\
Stem straightness & Family $\times$ Block & 208 & 0.002 & $4.284^{* *}$ \\
degree & Family & 52 & 0.096 & 1.157 \\
& Block & 4 & 0.365 & $4.525^{* *}$ \\
Stem form & Family $\times$ Block & 208 & 0.083 & $2.568^{* *}$ \\
& Family & 52 & 0.007 & $5.622^{* *}$ \\
& Block & 4 & 0.025 & $21.137^{* *}$ \\
Branch number & Family $\times$ Block & 208 & 0.004 & $3.502^{* *}$ \\
per node & Family & 52 & 5.355 & $3.834^{* *}$ \\
& Block & 4 & 3.079 & 2.205 \\
& Family $\times$ Block & 208 & 1.397 & $1.253^{*}$ \\
\hline
\end{tabular}

**Represents extremely significant differences at $p<0.01$, and *Represents significant differences at $p<0.05$, respectively

and V (0.65). SSD (degree of stem straightness) and BNN (branch number per node) were significantly $(p=0.04)$ correlated $(0.30)$. For wood traits, fiber length was significantly $(p<0.01)$ correlated with fiber width $(0.42)$ and fiber length to width ratio $(p<0.01 ; r=0.45)$, but fiber width was significantly $(p<0.05)$ negatively correlated $(-0.61)$ with fiber length to width ratio. In addition, holocellulose content was highly $(p<0.01)$ correlated with cellulose content $(0.70)$ and hemicellulose content (0.69). Lignin content was significantly $(p<0.01)$ correlated with DBH $(r=0.43)$ and volume $(r=0.42)$.

\section{Principal components analysis}

Principal Component Analysis (PCA) summarizes the information in five significant components (Table 4). The eigenvalue for component I was 3.584 with a contribution of $23.9 \%$; and the eigenvalues of $\mathrm{H}, \mathrm{DBH}, \mathrm{V}$, and SF were higher, and therefore component 1 mainly represented the growth traits. The eigenvalue for component II was 2.263, with a contribution of $15.1 \%$; and the eigenvalue of CC, $\mathrm{HEC}$, and HOC were higher, and therefore this component represented the wood chemical properties. The eigenvalue for component III was 1.935, with a contribution of $12.9 \%$; and the absolute eigenvalues of WD, FW, and LWR were higher, thus this component represented the physical properties of wood. The eigenvalue for component IV was 1.556, 
Table 2 ANOVA results for examining variations in wood traits among families
Table 3 Descriptive statistics for different growth and wood traits together with phenotypic coefficient of variation (PCV) and heritability $\left(h^{2}\right)$

\begin{tabular}{llrllr}
\hline Traits & Variance source & \multicolumn{1}{l}{ SS } & df & MS & \multicolumn{1}{l}{ F } \\
\hline Wood density & Family & $141,067.393$ & 52 & 2712.834 & $9.344 * *$ \\
Fiber length & Family & $76,120,014.064$ & 52 & $1,463,846$ & $6.038^{* *}$ \\
Fiber width & Family & $32,844.393$ & 52 & 631.623 & $17.782^{* *}$ \\
Length to width ratio & Family & $124,093.515$ & 52 & 2386.414 & $15.515^{* *}$ \\
Cellulose content & Family & 2775.195 & 52 & 53.369 & $21.342^{* *}$ \\
Hemicellulose content & Family & 2729.210 & 52 & 52.485 & $21.048^{* *}$ \\
Holocellulose content & Family & 5339.773 & 52 & 102.688 & $19.178^{* *}$ \\
Lignin content & Family & 3957.510 & 52 & 76.106 & $25.221^{* *}$ \\
Ash content & Family & 33.326 & 52 & 0.641 & $26.577^{* *}$ \\
\hline
\end{tabular}

$* *$ Represents extremely significant differences at $p<0.01$, and *Represents significant differences at $p<0.05$, respectively

\begin{tabular}{lccccrl}
\hline Traits & Mean & Max & Min & SD & PCV & h2 \\
\hline Height & 7.60 & 8.57 & 7.00 & 0.82 & 10.79 & 0.439 \\
DBH & 16.38 & 20.79 & 12.91 & 2.67 & 16.30 & 0.746 \\
Volume & 0.0770 & 0.1317 & 0.0464 & 0.0288 & 37.40 & 0.745 \\
Stem straightness degree & 3.94 & 4.43 & 3.33 & 0.78 & 19.80 & 0.136 \\
Stem form & 0.75 & 0.78 & 0.71 & 0.04 & 5.33 & 0.822 \\
Branch number per node & 5.56 & 6.58 & 4.47 & 1.14 & 20.50 & 0.739 \\
Wood density & 469.59 & 563.17 & 405.39 & 32.38 & 6.90 & 0.889 \\
Fiber length & 1772.06 & 2178.98 & 1431.91 & 531.41 & 29.99 & 0.834 \\
Fiber width & 31.58 & 41.66 & 23.31 & 7.42 & 23.49 & 0.944 \\
Length to width ratio & 56.93 & 78.63 & 45.25 & 15.06 & 26.45 & 0.936 \\
Cellulose content & 30.80 & 39.38 & 22.82 & 4.39 & 14.25 & 0.952 \\
Hemicellulose content & 16.03 & 29.32 & 9.25 & 4.35 & 27.14 & 0.953 \\
Holocellulose content & 46.83 & 58.31 & 36.05 & 6.12 & 13.07 & 0.948 \\
Lignin content & 23.67 & 34.94 & 15.70 & 5.20 & 21.97 & 0.960 \\
Ash content & 0.72 & 2.19 & 0.10 & 0.48 & 66.67 & 0.962 \\
\hline
\end{tabular}

with a contribution of $10.4 \%$; the eigenvalues of SSD and BNN were 0.643 and 0.659 , respectively. Therefore, this component represented the stem form traits. The cumulative contribution of the five principal components was $71.1 \%$, which provided most of the information on the growth and wood traits of the families.

\section{Family selection}

To improve the growth of $P$. koraiensis, $\mathrm{H}, \mathrm{DBH}, \mathrm{V}$, and SF were applied as evaluation indices of growth traits through principal components analysis. The results of multiple-trait comprehensive evaluation analysis are shown in Table 5 . At a $10 \%$ selection intensity, five families $(115,117,120$, 133 and 138) were identified as families with rapid growth. The selected families had $Q_{\mathrm{i}}$ values of $1.997,1.915,1.863$, 1.870 , and 1.917, and with average $\mathrm{H}, \mathrm{DBH}, \mathrm{V}$, and SF of $0.48 \mathrm{~m}, 2.66 \mathrm{~cm}, 0.0304 \mathrm{~m}^{3}$, and 0.02 , respectively whereas their genetic gains were $2.8 \%, 12.1 \%, 29.4 \%$, and $1.9 \%$, respectively.

High-quality materials for building and furniture construction could be obtained through the selection of families based on $\mathrm{H}, \mathrm{DBH}, \mathrm{V}, \mathrm{SF}$ of growth traits and WD, FW, and LWR of physical properties of wood as evaluation indices. The results of the multiple-trait comprehensive evaluation analysis are shown in Table 6 . At a 10\% selection intensity, five families $(112,115,117,135$, and 138) were identified as elite families for production of high-quality timber. The selected families had $Q_{\mathrm{i}}$ values $2.160,2.145,2.219,2.140$, and 2.126. Average H, DBH, V, SF, WD, FW and LWR were $8.0 \mathrm{~m}, 18.9 \mathrm{~cm}, 0.105 \mathrm{~m}^{3}, 0.8,488.4 \mathrm{~kg} \mathrm{~m}^{-3}, 28.4 \mu \mathrm{m}$ and 66.6 , whereas their genetic gains were $2.4 \%, 11.4 \%, 26.9 \%$, $1.8 \%, 3.6 \%,-9.5 \%$ and $15.9 \%$, respectively.

Families with superior pulp properties were selected via the multi-trait comprehensive evaluation of fiber length (FL), length/width ratio (LWR) and cellulose production per plant $(\mathrm{CP})$ as evaluation indices. The $Q_{\mathrm{i}}$ values are presented 
Fig. 1 Correlations between different growth and traits of $P$ koraiensis families (numbers are the correlation coefficients between different traits). Where H, DBH, V, SSD, SF, BNN, WD, FL, FW, LWR, CC, HEC, HOC. LC, and AC stand for height, diameter at breast height, volume, stem straightness degree, stem fullness, branch number per node, wood density, fiber length, fiber width, fiber length to width ratio, cellulose content, hemicellulose content, holocellulose content, lignin content and ash content, respectively. * Correlation is significant at $5 \%$ level and $* *$ Correlation is significant at $1 \%$ level

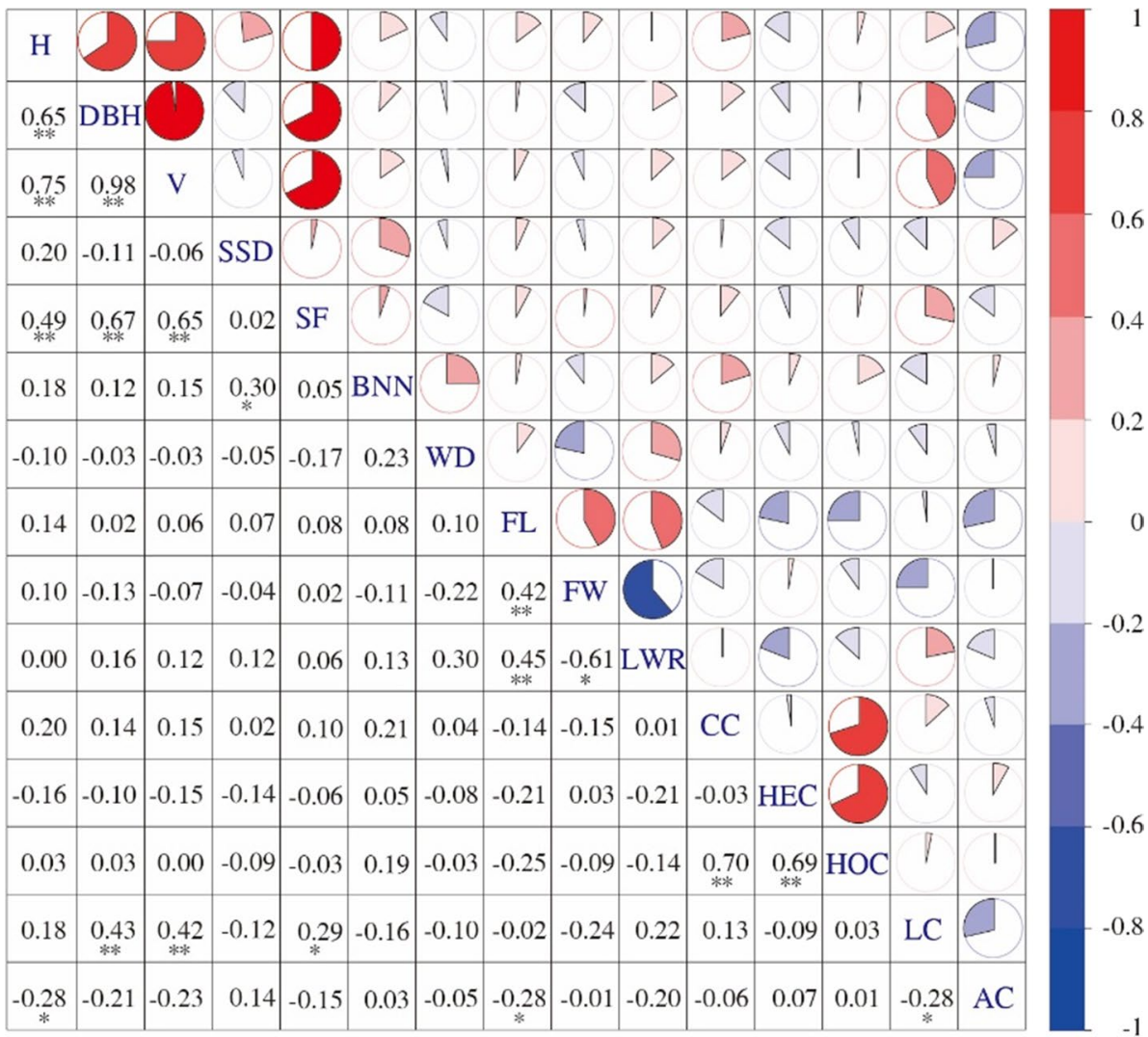

Table 4 Principal component analysis of different traits resulting in four distinct groupings that represented growth traits (Component I), chemical properties of wood (Component II), physical properties of wood (Component III) and stem form traits (Component IV)

\begin{tabular}{|c|c|c|c|c|c|}
\hline Principal component factor & Component I & Component II & Component III & Component IV & Component V \\
\hline Eigenvalue & 3.584 & 2.263 & 1.935 & 1.556 & 1.322 \\
\hline Contribution (\%) & 23.89 & 15.09 & 12.9 & 10.37 & 8.82 \\
\hline Cumulative contribution (\%) & 23.89 & 38.98 & 51.88 & 62.25 & 71.06 \\
\hline Height & 0.776 & 0.023 & -0.203 & 0.334 & -0.031 \\
\hline Diameter at breast height & 0.923 & 0.067 & -0.078 & -0.082 & -0.109 \\
\hline Volume & 0.942 & 0.036 & -0.116 & -0.001 & -0.102 \\
\hline Stem straightness degree & 0.007 & -0.135 & 0.174 & 0.643 & -0.367 \\
\hline Stem form & 0.74 & 0.057 & -0.231 & 0.034 & -0.105 \\
\hline Branch number per node & 0.164 & 0.171 & 0.385 & 0.659 & -0.037 \\
\hline Wood density & -0.042 & -0.145 & 0.586 & 0.095 & 0.212 \\
\hline Fiber length & 0.155 & -0.431 & -0.017 & 0.302 & 0.624 \\
\hline Fiber width & -0.144 & -0.124 & -0.785 & 0.366 & 0.375 \\
\hline Length to width ratio & 0.272 & -0.394 & 0.75 & -0.101 & 0.144 \\
\hline Cellulose content & 0.257 & 0.602 & 0.284 & 0.179 & 0.165 \\
\hline Hemicellulose content & -0.211 & 0.67 & -0.072 & -0.059 & 0.274 \\
\hline Holocellulose content & 0.034 & 0.914 & 0.153 & 0.086 & 0.315 \\
\hline Lignin content & 0.534 & 0.017 & 0.089 & -0.321 & 0.016 \\
\hline Ash content & -0.387 & 0.166 & -0.038 & 0.165 & -0.595 \\
\hline
\end{tabular}


Table $5 Q_{\mathrm{i}}$ value of different families that are suitable for improving growth
Table $6 Q_{\mathrm{i}}$ value of different families for improving timber for building material and furniture

\begin{tabular}{llllllllll}
\hline Family & Qi & Family & Qi & Family & Qi & Family & Qi & Family & Qi \\
\hline 115 & 1.997 & 90 & 1.839 & 101 & 1.808 & 114 & 1.764 & 132 & 1.740 \\
138 & 1.917 & 135 & 1.839 & 92 & 1.806 & 85 & 1.762 & 105 & 1.740 \\
117 & 1.915 & 144 & 1.838 & 65 & 1.804 & 84 & 1.762 & 145 & 1.738 \\
133 & 1.870 & 93 & 1.831 & 113 & 1.793 & 77 & 1.760 & 111 & 1.735 \\
120 & 1.863 & 1 & 1.825 & 49 & 1.784 & 109 & 1.751 & 97 & 1.735 \\
137 & 1.861 & 96 & 1.814 & 143 & 1.782 & 88 & 1.748 & 10 & 1.728 \\
134 & 1.853 & 140 & 1.813 & 100 & 1.778 & 102 & 1.747 & 87 & 1.693 \\
136 & 1.851 & 130 & 1.812 & 148 & 1.778 & 94 & 1.747 & 106 & 1.663 \\
129 & 1.851 & 122 & 1.812 & 125 & 1.777 & 83 & 1.744 & 91 & 1.652 \\
118 & 1.847 & 82 & 1.811 & 110 & 1.776 & 98 & 1.743 & & \\
112 & 1.845 & 108 & 1.809 & 163 & 1.768 & 103 & 1.742 & &
\end{tabular}

Note that the first five families are selected to be candidates for fast growth of P. koraiensis

\begin{tabular}{llllllllll}
\hline Family & Qi & Family & Qi & Family & Qi & Family & Qi & Family & Qi \\
\hline 117 & 2.219 & 134 & 2.057 & 82 & 2.013 & 113 & 1.972 & 105 & 1.931 \\
112 & 2.160 & 85 & 2.054 & 65 & 2.013 & 163 & 1.972 & 114 & 1.922 \\
115 & 2.145 & 118 & 2.051 & 10 & 2.013 & 97 & 1.969 & 102 & 1.912 \\
135 & 2.140 & 120 & 2.041 & 137 & 2.006 & 98 & 1.958 & 83 & 1.900 \\
138 & 2.126 & 129 & 2.040 & 136 & 2.004 & 122 & 1.953 & 87 & 1.897 \\
130 & 2.116 & 77 & 2.038 & 143 & 2.002 & 111 & 1.949 & 106 & 1.878 \\
1 & 2.113 & 101 & 2.036 & 90 & 1.991 & 132 & 1.942 & 109 & 1.870 \\
100 & 2.092 & 145 & 2.036 & 125 & 1.985 & 92 & 1.941 & 91 & 1.856 \\
84 & 2.091 & 93 & 2.031 & 94 & 1.981 & 110 & 1.940 & 103 & 1.851 \\
133 & 2.073 & 140 & 2.030 & 108 & 1.980 & 88 & 1.937 & & \\
144 & 2.064 & 96 & 2.028 & 148 & 1.978 & 49 & 1.933 & & \\
\hline
\end{tabular}

Note that the first five families are elite families suitable for improved production of timber for building materials and furniture

\begin{tabular}{llllllllll}
\hline Family & Qi & Family & Qi & Family & Qi & Family & Qi & Family & Qi \\
\hline 115 & 1.637 & 84 & 1.521 & 136 & 1.447 & 97 & 1.403 & 83 & 1.362 \\
117 & 1.619 & 113 & 1.507 & 138 & 1.444 & 114 & 1.401 & 110 & 1.356 \\
1 & 1.603 & 108 & 1.506 & 140 & 1.441 & 65 & 1.395 & 111 & 1.346 \\
112 & 1.593 & 145 & 1.500 & 10 & 1.436 & 132 & 1.393 & 93 & 1.343 \\
130 & 1.582 & 120 & 1.488 & 88 & 1.435 & 143 & 1.385 & 105 & 1.340 \\
129 & 1.572 & 125 & 1.485 & 49 & 1.427 & 102 & 1.381 & 109 & 1.334 \\
135 & 1.559 & 96 & 1.477 & 77 & 1.425 & 92 & 1.380 & 137 & 1.334 \\
100 & 1.543 & 144 & 1.466 & 106 & 1.410 & 98 & 1.376 & 87 & 1.320 \\
82 & 1.543 & 133 & 1.461 & 101 & 1.409 & 91 & 1.369 & 163 & 1.294 \\
134 & 1.530 & 90 & 1.456 & 118 & 1.407 & 103 & 1.368 & & \\
85 & 1.528 & 122 & 1.454 & 94 & 1.404 & 148 & 1.366 & & \\
\hline
\end{tabular}

Note that the first five families are selected to be the best suited families for improved production of pulpwood materials
Table $7 Q_{\mathrm{i}}$ value of different families for improving pulpwood materials in Table 7. At $10 \%$ selection intensity, five elite families $(1,112,115,117$, and 130) were chosen for the production of high- quality pulp. The selected families had $Q_{\mathrm{i}}$ values
1.603, 1.593, 1.637, 1.619, and 1.582. Average FL, LWR, and CP were $1934.02 \mu \mathrm{m}, 70.52$ and $16.01 \mathrm{~kg}$, and their real gains were $9.1 \%, 23.9 \%$, and $43.2 \%$, respectively. 


\section{Discussion}

\section{Variability in growth traits and wood physico-chemical properties}

Genetic variation drives evolution, which in turn enables the adaptation and survival of organisms under different environmental conditions (Cardoso et al. 2015). Therefore, to understand the genetic variation of forest growth, the growth and wood properties of 28-year-old half-sib families of $P$. koraiensis were evaluated. All wood traits and most of the growth traits were significantly different among families, which concurs with the findings of Yin (2017). Thus, there is room for improvement through the selection of elite families.

Assessment of inter- and intra-population variation is a prerequisite for developing effective forest genetic resource conservation strategies (Papi et al. 2012). In this research, a lower average of growth and wood traits was reported than those reported by Wang et al. (2018a), which may be ascribed to different tree ages. In addition, the HOC and LC of wood characteristics were lower, $46.8 \%$ and $23.7 \%$, respectively, which may be explained by the fact that the wood samples were too finely ground. Consequently, the exudation of the sample from the filter bag led to low experimental results.

The phenotypic coefficient of variation (PCV) is a widely adopted scaleless measure of variability (Wang et al. 2018b). It reflects the potential genetic variation among various traits in each population. Our study revealed that the PCV of $\mathrm{H}$, $\mathrm{DBH}$, and $\mathrm{V}$ was $10.8 \%, 16.3 \%$, and $37.4 \%$, respectively, lower than that of Eucalyptus urophylla S.T. Blake (Lu et al. 2010). The PCV of FL, FW, and LWR were $30.0 \%$, 23.5\%, and $26.4 \%$, respectively, higher than that of Eucalyptus camaldulensis Dehnh. (Shang et al. 2017. The PCV of CC, HEC and LC was $17.1 \%, 11.1 \%$, and $13.9 \%$, respectively and higher than those of Trachycarpus fortunei (Hook.) H. Wendl. reported by Hu and Zhao (2018). Results of the present study demonstrated abundant variations in growth and wood traits, which necessitates genetic improvement in different directions according to different breeding objectives.

Similarly, heritability is the measure of the degree to which parents pass on genetic characteristics to offspring (Abengmeneng et al. 2015). The heritability of each wood trait in this study was over 0.8 , significantly higher than that for Pinus massoniana Lamb. reported by Chen et al. (2015). These findings lay a foundation for the selection of families for pulpwood and building materials. Moreover, the heritability of $\mathrm{H}, \mathrm{DBH}$, and $\mathrm{V}$ in our study was $0.439,0.746$, and 0.745 , respectively. These values are higher than the results of Chen et al. (2016); higher heritability is beneficial for parents to pass on good characteristics to their offspring, making the selection of families more meaningful.

\section{Association between growth traits and wood properties}

There were highly significant positive correlations between height, diameter at breast height, and volume, which concur with the results of Liang et al. (2018) for different clones of $P$. koraiensis. In most cases, height, diameter, and volume production are used to evaluate genetic variation in tree growth. Because these traits are relatively easy to assess, they have become a common indicator for the evaluation of forestry production (Rweyongeza et al. 2005). In our study, there were strong correlations between height, diameter at breast height, and volume, which are beneficial to the evaluation and selection of fast-growing $P$. koraiensis families. Among wood physical properties, fiber length was significantly positively correlated with fiber width (0.422) and fiber length/width ratio (0.452). Similar results were reported by Wang (2009) who studied P. massoniana. The findings suggest the possibility of synchronized improvement of fiber length and width through selection of one of these traits. There was a highly significant correlation between holocellulose and cellulose (0.700) and hemicellulose contents (0.693), but lignin content was not strongly correlated with cellulose and hemicellulose contents, which is different from the results of Yin et al. (2017). This may be attributed to the fine grinding of the sample, whereby the sample leaks out of the filter bag and affects the calculation of cellulose, hemicellulose, and lignin contents. On the other hand, lignin was strongly correlated with diameter at breast height (0.432) and volume (0.420); this is different and contrary to findings from previous studies. For instance, Zhang et al. (2015a, b) reported the lack of a significant correlation between lignin content and growth traits of Populus tomentosa Carriére, whereas Yu (2015) reported a significant negative correlation between lignin content and growth traits of Larix gmelinii Ledebe ex Gordon. Therefore, the correlation of growth traits with wood properties is possibly related to different species and growing environments. The correlation analysis aimed to find the best linear combination between two sets of multivariate data that maximizes the correlation coefficient between them (Malacarne 2014). As a common statistical tool, correlation analysis can intuitively reflect the correlation between the datasets (Jendoubi and Strimmer 2019).

Principal components analysis (PCA) is a classic multivariate technique that reduces the dimensional complexity of a set of variables to a new set of unrelated variables, known as the principal component, which retains all the variable information (Fernández et al. 2015). It is applicable in the exploration of the relationship between different tree characters (Hoeber et al. 2014). In this study, all traits were divided into five principal components with a cumulative contribution rate of $71.1 \%$, lower than the results of a study by López de Heredia et al. (2009) on oaks. Following the analysis, 
principal component factors described growth traits, wood chemical properties, wood physical properties, and stem form. Each principal component objectively reflected the relationship among the analyzed traits and provided a basis for the evaluation and selection of elite families.

\section{Selection of elite families}

To select elite $P$. koraiensis families with different attributes, the families were screened according to three breeding objectives: fast-growth, production of high-quality construction timber, and production of pulpwood.

\section{Fast growing families}

Regarding best growth in height, diameter, volume, and stem fullness, five elite families were selected that had better growth for timber production and urban planting. These elite families showed $2.8 \%, 12.1 \%, 29.4 \%$, and $1.9 \%$ genetic gain in height, diameter, volume, and stem fullness, respectively. The results were higher than that reported for P. koraiensis by Wang et al. (2018a), and similar to a study on Douglas-fir (Clair et al. 2004). The growth performance of these selected elite families was good; thus they can be used as source of planting material for the establishment of fast-growing $P$. koraiensis plantations. Elite families with higher genetic gains are beneficial to promote and apply in forestry production.

\section{Families suitable for production of high quality building materials}

To obtain high-quality materials for building and furniture, height, diameter, volume, stem fullness, density, fiber width, and fiber length/width ratio were used as indicators for comprehensive evaluation based on the results of principal component analysis. Principal component analysis found wood density and fiber length to width ratio as representing the physical properties of wood. Wood density is an important feature of trees that is central to many functional processes, and is considered a trait that powerfully integrates various wood characteristics (Woodall et al. 2015). It directly affects wood quality. Fiber width and the ratio between fiber length and width are common wood fiber characteristics. Some studies have shown that fiber width is related to the wood structure, which is applied to judge the thickness of the wood (Huang and Chen 2014). A fine wood structure implies that the material is more compact, the surface is smoother, and is easier to cut and machine. Following the screening of 53 P. koraiensis families, 5 elite families with these characteristics were identified. The genetic gains of each trait were $2.4 \%, 11.4 \%, 26.9 \%, 1.8 \%, 3.6 \%,-9.5 \%$, and $15.9 \%$ for height, diameter, volume, stem fullness, density, fiber width, and fiber length/width ratio, respectively, higher than those reported by Wang et al. (2018a). The wood density of elite families was relatively high at $488.4 \mathrm{~kg} \mathrm{~m}^{-3}$. The selected elite families can be utilized for structural and decorative materials, including floor platforms and garden furniture.

\section{Families suitable for pulpwood production}

There are limited studies on the pulpwood production of $P$. koraiensis. However, given its long fiber length $(0.90-3.00 \mathrm{~mm})$, P. koraiensis is highly suitable to produce high-strength paper (Wang 2000). Therefore, the utilization value of $P$. koraiensis for pulpwood was evaluated. Fiber length, length/width ratio, and cellulose production were evaluation indices for pulpwood. Notably, the nature of wood determines its economic value and directly affects wood processing and utilization. Fiber length is the most important morphological parameter in papermaking. Wang et al. (2016) showed that longer fibers could achieve higher tear strength, tensile strength, and flexural strength. The length/width ratio of fiber is an important morphological index second only to fiber length. A larger length/width ratio is related to a larger bonding area of the fiber, a higher paper index, and higher paper strength (Chang et al. 2007). In this study, 5 elite families were identified using fiber length, length/width ratio, and cellulose production as evaluation indexes. The real gains were $9.1 \%, 23.9 \%$, and $43.2 \%$, respectively. The genetic improvement is remarkable and can provide valuable material with fine quality fiber.

\section{Conclusion}

We examined variations in growth and wood properties of 53 half-sib families of $P$. koraiensis. Substantial genetic variations in growth traits and wood physicochemical properties were found among families with good heritability, which in turn enabled selection of elite families. Consequently, five elite families that had better growth for timber production and urban planting; five families suitable for production of high-quality building materials; and five elite families suitable for pulpwood production were selected, with good genetic gain. Thus, these families should be used in future plantation establishment to achieve economic objectives.

Author contributions QHZ, CLZ, MT and XYZ conceived and designed the project, and QHZ, XNP, XBL and CLZ performed the experiments and wrote the manuscript. GZD, WLS, LKW and YLL assisted in conducting the experiments and analyzing the data. MT revised and edited the manuscript. All the authors read and approved the final manuscript.Open Access This article is licensed under a Creative Commons Attribution 4.0 International License, which permits use, sharing, adaptation, distribution and reproduction in 
any medium or format, as long as you give appropriate credit to the original author(s) and the source, provide a link to the Creative Commons licence, and indicate if changes were made. The images or other third party material in this article are included in the article's Creative Commons licence, unless indicated otherwise in a credit line to the material. If material is not included in the article's Creative Commons licence and your intended use is not permitted by statutory regulation or exceeds the permitted use, you will need to obtain permission directly from the copyright holder. To view a copy of this licence, visit http://creativecommons.org/licenses/by/4.0/.

\section{References}

Abengmeneng CS, Ofori DA, Kumapley PK, Akromah R, Jamnadass $R$ (2015) Estimation of heritability and genetic gain in height growth in Ceiba pentandra. Afr J Biotechnol 14(22):1880-1885

Cardoso JGR, Andersen MR, Herrgard MJ, Sonnenschein N (2015) Analysis of genetic variation and potential applications in genome-scale metabolic modeling. Front Bioeng Biotechnol 3(13): $1-12$

Chang SS, Liu Y, Hu JB, Wu YQ, Zhu LF, Hu YC (2007) Study on anatomical structure and fiber morphology of Eucalyptus urophylla family wood. Pap Sci Technol 26(04):1-5

Chen DX (2001) Review on the progress of forest tree genetic improvement in China. Guangxi for Sci. https://doi.org/10. 19692/j.cnki.gfs.2001.s1.004 (in Chinese)

Chen XY, Shen XH (2005) Forest tree breeding. Higher Education Press, Beijing, p 111

Chen MM, Feng FJ, Sui X, Han SJ (2011) Comparison of application of three molecular marker methods in map construction of Pinus koraiensis. Non-Wood for Res 29(04):13-16. https://doi.org/10. 14067/j.cnki.1003-8981.2011.04.020 (in Chinese)

Chen TQ, Zhu YY, Zhao Y, Li YP, Xie WB (2015) Analysis on genetic variation of wood properties of Pinus massoniana half-sib progeny. J Cent South Univ for Technol 35(02):38-43. https://doi.org/10.14067/j.cnki.1673-923x.2015.02.008 (in Chinese)

Chen H, Feng YH, Su WB, Liang YY, Liang GF, Yang ZQ (2016) Growth characters and family selection of open pollination progeny in 21-year-old Pinus massoniana seed orchard. J West China for Sci 45(06):14-18. https://doi.org/10.16473/j.cnki.xblykx1972. 2016.06 .003 (in Chinese)

Clair JBS, Mandel NL, Jayawickrama KJS (2004) Early realized genetic gains for coastal douglas-fir in the northern oregon cascades. Western J Appl for 19(3):195-201. https://doi.org/10.1093/ wjaf/19.3.195

Feng FJ, Sui X, Chen MM, Zhao D, Han MM, Li MH (2010) Mode of pollen spread in clonal seed orchard of Pinus koraiensis. J Biophys Chem 1(1):33-39. https://doi.org/10.4236/jbpc.2010.11004

Fernández D, Cañellas I, Barbeito I, González M, Ledo A (2015) Alternative approaches to assessing the natural regeneration of Scots pine in a Mediterranean forest. Ann for Sci 72(5):569-583. https:// doi.org/10.1007/s13595-015-0479-4

Han Q, Zhong CL, Zhang Y, Jiang QB, Chen Y, Chen Z, Khongsak P (2017) Genetic variation and selection of Casuarina junghuhniana provenances at Lingao, Hainan. For Res 30(4):595-603. https://doi.org/10.13275/j.cnki.lykxyj.2017.04.009 (in Chinese)

Hoeber S, Leuschner C, Köhler L, Arias-Aguilar D, Schuldt B (2014) The importance of hydraulic conductivity and wood density to growth performance in eight tree species from a tropical semi-dry climate. For Ecol Manage 330:126-136. https://doi.org/10.1016/j. foreco.2014.06.039
Hu ZJ, Zhao Y (2018) Geographic variation of Trachycarpus fortunei in Guizhou Province. J West China for Sci 47(02):7-14. https:// doi.org/10.16473/j.cnki.xblykx 1972.2018.02.002 (in Chinese)

Huang RM, Chen CD (2014) The research on wood fiber length and width of 42 kinds of hardwood. J Minxi Vocat Tech Coll 16(4):97-102. https://doi.org/10.3969/j.issn.1673-4823.2014.04. 025

Imbs AB, Pham LQ (1996) Fatty acids and triacylglycerols in seeds of Pinaceae species. Phytochemistry 42(4):1051-1053. https://doi. org/10.1016/0031-9422(96)00098-2

Jendoubi T, Strimmer K (2019) A whitening approach to probabilistic canonical correlation analysis for omics data integration. BMC Bioinf 20(1):1-13. https://doi.org/10.1186/s12859-018-2572-9

Kim ZS, Hwang JW, Lee SW, Yang C, Gorovoy PG (2005) Genetic variation of Korean pine (Pinus koraiensis Sieb. et Zuc.) at allozyme and RAPD markers in Korea, China and Russia. Silvae Genet 54(4/5):235-246. https://doi.org/10.1515/sg-2005-0034

Kim JH, Lee HJ, Jeong SJ, Lee MH, Kim SH (2012) Essential oil of Pinus koraiensis leaves exerts antihyperlipidemic effects via up-regulation of low-density lipoprotein receptor and inhibition of acyl-coenzyme A: cholesterol acyltransferase. Phytother Res 26(9):1314-1319. https://doi.org/10.1002/ptr.3734

Kjaer ED, Foster GS (1996) The economics of tree improvement of teak (Tectona grandis L.). Technical Note. Danida Forest Seed Centre, Copenhagen, $\mathrm{p} 43$.

Lee TK, Park JY, Yu JS, Jang TS, Oh ST, Pang C, Ko YJ, Kang KS, Kim KH (2018) 7 $\alpha, 15$-Dihydroxydehydroabietic acid from Pinus koraiensis inhibits the promotion of angiogenesis through downregulation of VEGF, p-Akt and p-ERK in HUVECs. Bioorg Med Chem Lett 28(6):1084-1089

Li SQ (2018) Analysis of genetic variation of half-sibs in the seed orchard of Cryptomeria fortune. J Jiangsu Sci Technol 45(5):10 13. https://doi.org/10.3969/j.issn.1001-7380.2018.05.002 (in Chinese)

Li RL, Huang SX, Liang J, Zhou CM, He CM, Li LM, Tang GQ (2014) Genetic variation of growth traits and wood properties in Chinese fir clones. J South Agric 45(09):1626-1631. https://doi.org/10. 3969/j:issn.2095-1191.2014.9.1626 (in Chinese)

Li QY, Zhong CL, Jiang QB, Zhang Y, Chen Y, Wei YC, Chen Z (2018) Genetic variations and primary selections of main wood properties among Michelia macclurei families. J South China Agric Univ 39(4):73-79. https://doi.org/10.7671/j.issn.1001411X.2018.04.012 (in Chinese)

Liang DY, Ding CJ, Zhao GH, Leng WW, Zhang M, Zhao XY, Qu GZ (2018) Variation and selection analysis of Pinus koraiensis clones in northeast China. J for Res 29(3):611-622. https://doi.org/10. 1007/s11676-017-0471-y

Lindgren D, Prescher F (2005) Optimal clone number for seed orchards with tested clones. Silvae Genet 54(48):80-92. https://doi.org/10. 1080/02827580510008329

Liu DD (2017) Advances in breeding of improved Pinus koraiensis varieties in China. Prot for Sci Technol 3:96-99

Liu HW, Sun MO, Wang GY (2015) Study on the establishment technology of the second generation clonal seed orchard of Pinus koraiensis. For Sci Technol 40(06):13-15

Liu XC (2004) A study on technique of clonal selection and grafting of Pinus koariensis with high seed production. Master's Thesis of Northeast Forestry University.

López de Heredia U, Valbuena-Carabaña M, Córdoba M, Gil L (2009) Variation components in leaf morphology of recruits of two hybridising oaks [Q. petraea (Matt.) Liebl. and Q. pyrenaica Willd.] at small spatial scale. Eur J for Res 128(6):543-554. https://doi.org/10.1007/s10342-009-0302-6

Lu ZH, Xu JM, Li GY, Bai JY, Huang HJ, Hu Y (2010) Study on multicharacters genetic analysis and selection index of 93 Eucalyptus 
urophylla clones. Eucalypt Sci Technol 27(01):1-8. https://doi. org/10.13987/j.cnki.askj.2010.01.002 (in Chinese)

Luo JX, Li XQ, Sun P, Wang YH, Hu GR, Wang FL, Zheng W (2004) Variation pattern of tracheid and wood density in natural populations of Picea asperata. J Beijing for Univ 26(6):80-85. https:// doi.org/10.13332/j.1000-1522.2004.06.017 (in Chinese)

Luo RJ, Hu ZQ, Song W, Xu CW (2010) A rank-sum-difference testing method for multi-trait comprehensive ranking. Sci Agric Sin 43(10):2008-2015. https://doi.org/10.3864/j.issn.0578-1752. 2010.10.005 (in Chinese)

Makoto K, Koike T (2007) Effects of nitrogen supply on photosynthetic and anatomical changes in current-year needles of Pinus koraiensis, seedlings grown under two irradiances. Photosynthetica 45(1):99-104. https://doi.org/10.1007/s11099-007-0015-3

Malacarne RL (2014) Canonical correlation analysis. Math J 16:1-22

Matziris D (1997) Variation in growth, flowering and cone production in a clonal seed orchard of Aleppo pine grown in Greece. Silvae Genetica 46(4):224-228

Metougui ML, Mokhtari M, Maughan PJ, Jellen EN, Benlhabib O (2017) Morphological variability, heritability and correlation studies within an Argan tree population (Argania spinosa (L.) Skeels) preserved in situ. Int J Agric for 7(2):42-51. https://doi. org/10.5923/j.ijaf.20170702.02

Oh CY, Kang KS, Choi WY, Han SU, Kim CS (2008) Genetic gain and diversity in a clonal seed orchard of Pinus koraiensis under various thinning intensities. Korean J Breed Sci 40(3):263-268. https://doi.org/10.1016/S0140-6736(00)30169-6

Papi RM, Spanos KA, Kyriakidis DA (2012) Genetic variation of Fraxinus angustifolia natural populations in Greece based on nuclear and chloroplast microsatellite markers. Eur J for Res 131(4):11511161. https://doi.org/10.1007/s10342-011-0586-1

Ru GX, Feng S, Yuan JL, Zhang GS, Wu YL (2001) Study on inheritance and variation of wood basic density of Paulownia clone. J Henan Agric Univ 35(4):335-338. https://doi.org/10.16445/j.cnki. 1000-2340.2001.04.010 (in Chinese)

Rweyongeza DM, Yeh FC, Dhir NK (2005) Heritability and correlations for biomass production and allocation in White spruce Seedlings. Silvae Genetica 54(4):228-235. https://doi.org/10. 1515/sg-2005-0033

Shang XH, Zhang PJ, Xie YJ, Luo JZ, Li C, Wu ZH (2017) Wind resistance correlated to growth and wood properties of $50 \mathrm{Euca}$ lyptus camaldulensis provenance families. J Zhejiang A F Univ 34(6):1029-1037. https://doi.org/10.11833/j.issn.2095-0756. 2017.06.009 (in Chinese)

Shpatov AV, Popov SA, Salnikova OI, Kukina TP, Shmidt EN, Um BH (2017) Composition and bioactivity of lipophilic metabolites from needles and twigs of Korean and Siberian pines (Pinus koraiensis Siebold \& Zucc. and Pinus sibirica Du Tour). Chem Biodivers 14(2):e1600203. https://doi.org/10.1002/cbdv.201600203

Silva FFD, Pereira MG, Ramos HCC, Junior PCD, Pereira TNS, Gabriel APC, Viana AP, Ferreguetti GA (2008) Selection and estimation of the genetic gain in segregating generations of papaya (Carica papaya L.). Crop Breed Appl Biotechnol 8(1):1-8. https://doi.org/10.1089/clo.2007.0047

Son Y, Hwang JW, Kim ZS, Lee WK, Kim JS (2001) Allometry and biomass of Korean pine (Pinus koraiensis) in central Korea. Bioresour Technol 78(3):251-255. https://doi.org/10.1016/S09608524(01)00012-8

Song YP, Cai YQ, Yan CF (2007) Study on applications of grafting technique in cultivating fruit-harvest forest of Pinus koraiensis clones. For Invest Des 2:47-48 (in Chinese)

Su BQ (2001) The analyses of wood densities and growth heredity stability of Cunninghamia lanceolata fine families. J Fujian for Sci Technol. https://doi.org/10.13428/j.cnki.fjlk.2001.s1.001 (in Chinese)
Sun YR, Zhu JJ, Sun JX, Yan QL (2016) Photosynthetic and growth responses of Pinus koraiensis seedlings to canopy openness: implications for the restoration of mixed-broadleaved Korean pine forests. Environ Exp Bot 129:118-126. https://doi.org/10.1016/j. envexpbot.2016.02.005

Sun DY, Yang WX, Liu QL, Fang SZ (2018) A study on geographic variation in wood microfibril angle of Cyclocarya paliurus. J Nanjing for Univ (nat Sci Ed) 42(03):81-85. https://doi.org/10.3969/j. issn.1000-2006.201606005 (in Chinese)

Tang S, Sun ZB, Ma CM (2018) Radial variation of anatomical properties of Betula platyphylla wood in different slope directions of northern Hebei province. J Southwest for Univ (not Sci) 38(03):157-165. https://doi.org/10.11929/j.issn.2095-1914.2018. 03.023 (in Chinese)

Wang H (2013) Research progress and development trend of tree seed orchard. World for Res 26(04):32-37. https://doi.org/10.13348/j. cnki.sjlyyj.2013.04.012 (in Chinese)

Wang S, Li HR, Zhao YH, Zhen Z (2015) Distribution of natural Korean pines in Baihe Forestry Bureau based on spatial models. J Beijing for Univ 37(10):73-85. https://doi.org/10.13332/j.10001522.20150105 (in Chinese)

Wang JF, Liang XJ, Li KX, Hu C, Lu ZX, Chen JJ (2016) Comparative analysis on wood anatomical characteristics of Cinnamomum cassia from Xijiang and Cinnamomum cassia var. macrophyll. Guangxi for Sci 45(01):75-80. https://doi.org/10.19692/j.cnki.gfs. 2016.01.014 (in Chinese)

Wang F, Zhang QH, Tian YG, Yang SC, Wang HW, Wang LK, Li YL, Zhang P, Zhao XY (2018a) Comprehensive assessment of growth traits and wood properties in half-sib Pinus koraiensis families. Euphytica 214(11):202. https://doi.org/10.1007/ s10681-018-2290-4

Wang DL, Formica MK, Liu S (2018b) Nonparametric interval estimators for the coefficient of variation. Int J Bio 14(1):1-15. https:// doi.org/10.1515/ijb-2017-0041

Wang HM (2000) Study on genetic variation and selection for optimal provenance of Pinus koraiensis. Master's Thesis of Northeast Forestry University.

Wang J (2009) Wood property analysis on different clones for pulpwood in clonal seed orchard of Pinus massoniana. Master's Thesis of Nanjing Forestry University.

Woodall CW, Russel MB, Walters BF, D'Amato AW, Zhu K, Saatchi SS (2015) Forest production dynamics along a wood density spectrum in eastern US forests. Trees 29(1):299-310. https://doi.org/ 10.1007/s00468-014-1083-1

Wu DS, Liang JM, Yang ZQ, Huang YL (2018) Genetic variation and index selection of growth and resin yield of 20-year halfsib families of Pinus massoniana. J Zhejiang for Sci Technol 38(02):8-13. https://doi.org/10.3969/j.issn.1001-3776.2018.02. 002 (in Chinese)

Xia DA, Yang SW, Yang CP, Lv QY, Liu GF, Zhang PG (1991) Experimental study on provenance of Pinus koraiensis (I) preliminary regionalization of provenance. J Northeast for Univ S2:122-128 (in Chinese)

Xia H, Zhao GH, Zhang LS, Sun XY, Yin SP, Liang DY, Li Y, Zheng M, Zhao XY (2016) Genetic and variation analyses of growth traits of half-sib Larix olgensis families in northeastern China. Euphytica 212(3):387-397. https://doi.org/10.1007/ s10681-016-1765-4

Xue JG, Wang CC, Xu CL (2009) Study on the construction technology of Pinus koraiensis seed orchard. New Technol New Prod China 19:226-226

Ye DQ (2011) Open pollination progeny test and excellent family selection of Liquidambar formosana. J Cent South Univ for Technol 31(08):79-82. https://doi.org/10.14067/j.cnki.1673-923x.2011. 08.035 (in Chinese) 
Yin SP, Xiao ZH, Zhao GH, Zhao X, Sun XY, Zhang Y, Wang FW, Li SC, Zhao XY, Qu GZ (2017) Variation analyses of growth and wood properties of Larix olgensis clones in China. J for Res 28(04):687-697. https://doi.org/10.1007/s11676-016-0359-2

Yu HY (2015) Superior provenances selection of Larix olgensis in different sites based on analytic timber. Master's Thesis of Northeast Forestry University.

Zhang XB, Li Y, Yuan HW, Li W, Fu YH, Liu ZY, Zhu SL (2014) Genetic variations of growth traits in a 21 -year-old stand progeny of Shanxi natural Pinus tabuliformis forests. J Beijing for Univ 36(03):104-109. https://doi.org/10.13332/j.cnki.jbfu.2014.03.016 (in Chinese)

Zhang PD, Wu F, Kang XY (2015a) Chemical properties of wood are under stronger genetic control than growth traits in Populus tomentosa Carr. Ann for Sci 72(1):89-97. https://doi.org/10.1007/ s13595-014-0401-5

Zhang Y, Yi XM, Wang YX, Ji LZ, Wu PL (2015b) Impact of tree harvesting on the population structure and dynamics of Pinus koraiensis (Pinaceae). Acta Ecol Sin 35(01):38-45. https://doi. org/10.5846/stxb201403250544 (in Chinese)

Zhang XX, Xia H, Zhao X, Zhang Y, Li GY, Zhang L, Sun XY, Han DH, Zhao XY (2017) Comprehensive evaluation of growth and fruit traits of Larix olgensis parents in seed orchard. Bull Bot Res 37(06):933-940 (in Chinese)

Zhao XY, Bian XY, Liu MR, Li ZX, Li Y, Zheng M, Teng WH, Jiang J, Liu GF (2014) Analysis of genetic effects on a complete diallel cross test of Betula platyphylla. Euphytica 200(2):221-229. https://doi.org/10.1007/s10681-014-1147-8

Zhao XY, Xia H, Wang XW, Wang C, Liang DY, Li KL, Liu GF (2016) Variance and stability analyses of growth characters in half-sib Betula platyphylla families at three different sites in China. Euphtyica 208(1):173-186. https://doi.org/10.1007/ s10681-015-1617-7

Zhen YP, Sun HY, Dong RX, Hua CH, Tang SQ, Zhang JZ, Fu SH (2007) A study on realized and genetic gains of different generations and types in seed orchards of Chinese fir (Cunninghamia lanceolata). Sci Silvae Sin 43(3):20-27 (in Chinese)

Publisher's Note Springer Nature remains neutral with regard to jurisdictional claims in published maps and institutional affiliations. 